\title{
CONFLITOS DA ARBORIZAÇÃO COM ELEMENTOS URBANOS NA CIDADE DE VALENÇA, ESTADO DO RIO DE JANEIRO
}

\author{
AFFORESTATION CONFLICTS WITH URBAN ELEMENTS IN THE CITY OF \\ VALENÇA, STATE OF RIO DE JANEIRO
}

\author{
Vagner Luiz Cardoso de Medeiros Cunha ${ }^{1}$, Luís Mauro Sampaio Magalhães², \\ Welington Kiffer de Freitas ${ }^{3}$, Bruno Araujo Furtado de Mendonça ${ }^{4}$
}

\begin{abstract}
RESUMO
O planejamento da arborização tem grande importância na gestão urbana, a fim de evitar ou minimizar os conflitos que ainda podem causar prejuízos nas estruturas públicas ou privadas. Nesse estudo foi realizado um inventário da arborização na região central de Valença, cidade turística do estado do Rio de Janeiro, com registro dos conflitos de árvores com a fiação, acesso, iluminação, portões e garagens, recuo do meio fio e serviços subterrâneos. As ruas foram categorizadas e a maior parte delas apresentou característica de via residencial $(67,3 \%)$ seguida de uso misto $(20,8 \%)$ e por fim uso comercial $(11,9 \%)$. Do total de árvores levantadas, $45 \%$ apresentam conflitos com a fiação telefônica e $38 \%$ com a fiação elétrica, os maiores valores dentre todos os elementos urbanos. Um número bastante alto apresentou sinais de podas, indicando conflitos anteriores e demonstrando forte intervenção nestes indivíduos. Estes resultados estão de acordo com estudos realizados em diferentes espaços urbanos onde não foi observado planejamento, que também mostram percentuais elevados de conflitos e uma alta demanda por intervenções.
\end{abstract}

Palavras-chave: Inventário Arbóreo; Planejamento; Estruturas urbanas, Árvores Urbanas, Intervenções Urbanas.

\begin{abstract}
Afforestation planning is of great importance in urban management in order to avoid or minimize conflicts that may cause damage to public or private structures. In this study, an afforestation inventory was carried out in the central region of Valença, a tourist city in the state of Rio de Janeiro, with records of tree conflicts with wiring, access, lighting, gates and garages, curb and underground services. The streets were categorized and most of them had residential road characteristics $(67.3 \%)$ followed by mixed use $(20.8 \%)$ and finally commercial use (11.9\%). Of the total trees surveyed, $45 \%$ have conflicts with telephone wiring and $38 \%$ with electrical wiring, the highest values among all urban elements. A very high number of trees showed signs of pruning, indicating earlier conflicts and demonstrating strong intervention in these individuals. These results are consistent with studies in different types of urban spaces without planning, which also show high percentages of conflict and a high demand for interventions.
\end{abstract}

Keywords: Tree Inventory; Planning; Urban structures; Urban tree, Urban Interventions.

\section{INTRODUÇÃO}

\footnotetext{
Recebido em 22.10.2019 e aceito em 24.04.2020

1 Engenheiro Florestal. Mestre. Secretaria Municipal de Valença. Valença/RJ. Email: ruralvagner@gmail.com

2 Engenheiro Florestal. Doutor. Professor Titular. Universidade Federal Rural do Rio de Janeiro. Seropédica/RJ. Email: I.mauro@terra.com.br

3 Engenheiro Florestal. Doutor. Professor Adjunto. Universidade Federal Fluminense. Email: wkfreitas@gmail.com

4 Engenheiro Florestal. Doutor. Professor Adjunto. Universidade Federal Rural do Rio de Janeiro. Seropédica/RJ. Email: brunoafmendonca@gmail.com
} 
O planejamento do plantio arbóreo na área urbana deve ser pautado em critérios técnicos adequados de forma a mitigar os danos materiais com os elementos urbanos como muros e calçadas visando à melhoria do ambiente, bem como para o próprio indivíduo arbóreo (MARTELLI; BARBOSA, 2011). Em estudo realizado em Garanhuns - PE, Chaves, Silva e Amador (2013) observaram a falta de sincronia da arborização urbana viária com o planejamento urbano como um dos problemas causadores dos conflitos entre a estrutura urbana da cidade e os elementos arbóreos.

Assim, os benefícios da arborização em vias públicas condicionam-se à qualidade de seu planejamento de forma a permitir ao poder público realizar intervenções necessárias, já que a falta de planejamento para o plantio pode ocasionar a necessidade de remediações futuras com o intuito de adaptar as condições em que os espécimes arbóreos foram plantados e solucionar diversos problemas referentes aos conflitos com a estrutura urbana (PIVETTA; SILVA FILHO, 2002). Seguindo estes conceitos, levantamentos da arborização em diversas cidades, incluindo algumas do Estado do Rio de Janeiro, apontam problemas frequentes e muitas vezes graves envolvendo conflitos entre a arborização e os demais elementos estruturais urbanos (CAICHE et al., 2016; MAYER; OLIVEIRA FILHO; BOBROWSKI, 2015).

Para Teixeira, Silva e Tatsch (2011), as condições ambientais adversas que as árvores encontram nas cidades quando comparadas com ambientes naturais, incluem a falta de espaço suficiente para o seu desenvolvimento, injúrias mecânicas ocasionadas por veículos, a qualidade do ar composta de partículas de poluição, pavimentação inadequada, estrangulamento por falta de gola (estruturas de proteção e delimitação da base da árvore), sistema radicular em conflito com serviços subterrâneos, tais como redes de gás e água e outras tubulações de concessionárias de serviços públicos.

Considerando estes aspectos, o presente trabalho teve como objetivo quantificar a arborização viária na Zona Central do $1^{\circ}$ Distrito de Valença - RJ, de forma a identificar os conflitos existentes, subsidiar o seu manejo e auxiliar na elaboração de futuros planos de gestão. A escolha da área justifica-se pelos espaços de destaque para o poder público, onde se localizam a Prefeitura e a Câmara Municipal, os terminais de ônibus, as praças históricas como o Jardim de Cima (Praça Visconde do Rio Preto) e o Jardim de Baixo (Praça XV de Novembro) sendo uma importante área de sensibilização quanto à necessidade de realização de um diagnóstico arbóreo.

\section{MATERIAL E MÉTODOS}


A área de estudo está localizada no Centro de Valença, cidade turística do estado do Rio de Janeiro, localizado na mesorregião Sul-fluminense e microrregião de Barra do Piraí, com municípios limítrofes: Barra do Piraí, Barra Mansa, Quatis, Rio das Flores, Vassouras, Passa Vinte - MG, Rio Preto - MG, Santa Rita de Jacutinga - MG, Santa Bárbara do Monte Verde - MG (Figura 1) (IBGE, 2019).

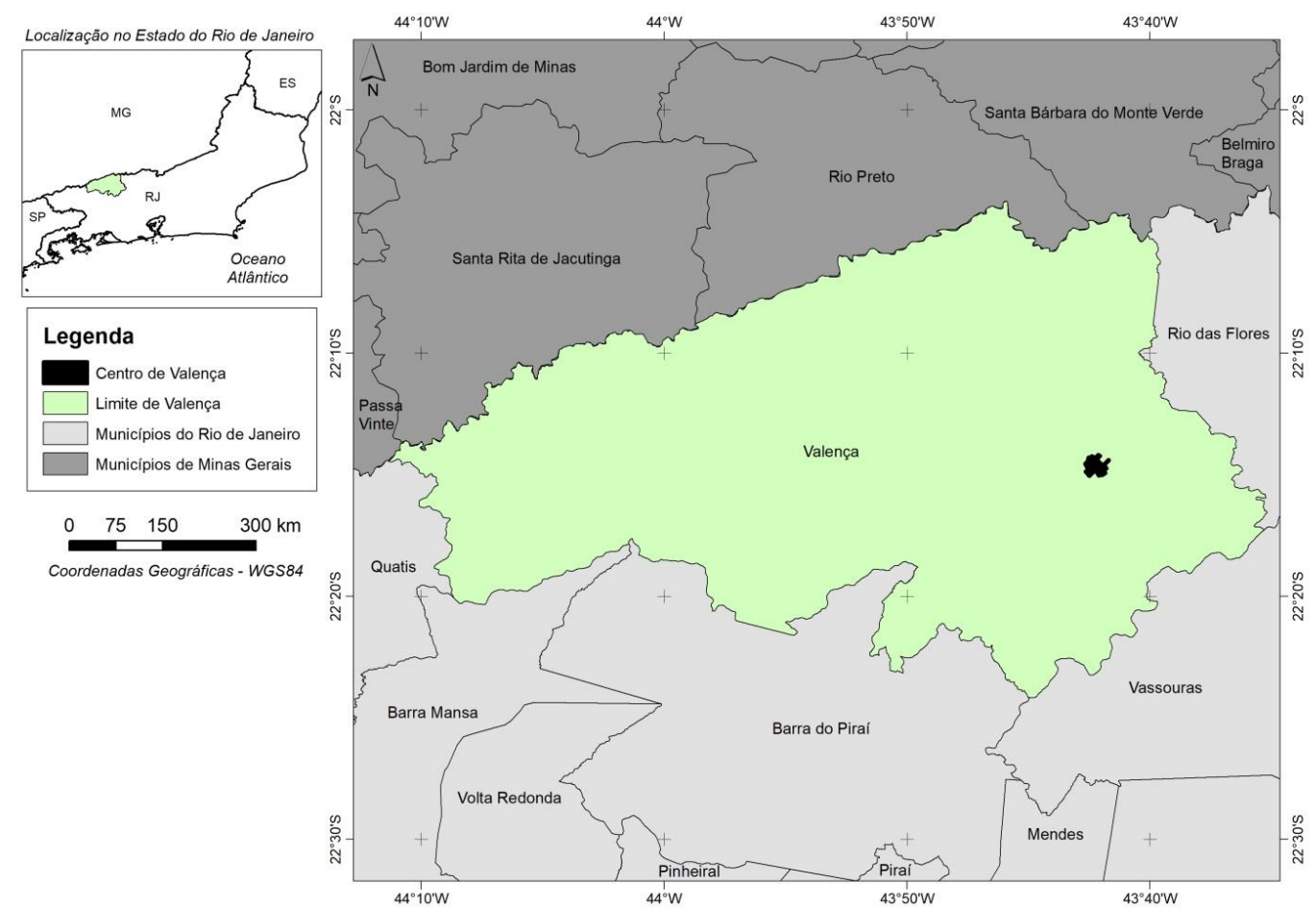

Figura 1. Localização do município de Valença no Estado do Rio de Janeiro e municípios vizinhos

Figure 1. Location of the municipality of Valença, in the state of Rio de Janeiro and municipalities surrounding

A cidade possui uma população estimada em 71.843 habitantes, dos quais $86,6 \%$ residem em área urbana, e apresenta densidade demográfica de 55,06 hab/ $\mathrm{km}^{2}$ (IBGE, 2019). A área de estudo localiza-se na bacia hidrográfica do Rio Paraíba do Sul e está inserida na microbacia do Rio das Flores (COMITÊ DE BACIAS HIDROGRÁFICAS, 2017).

Utilizando-se o mapa da Zona Central do município, integrante do Plano Diretor Participativo de Valença, os limites para delimitação da área de estudo foram estimados com o auxílio do Google Earth em 1,6 km².

O clima no município é classificado como tropical de Altitude Cwa, onde a maior concentração das chuvas ocorre no verão e pouca quantidade no inverno (ALVARES et al., 2013); as temperaturas médias mensais obtidas das estações meteorológicas de Valença variaram de um mínimo de $17,4 \stackrel{\circ}{ } \mathrm{C}$ em julho a um máximo de 23,7 $9 \mathrm{C}$ em fevereiro, com média anual de $20,7^{\circ} \mathrm{C}$ e pluviosidade média anual de $1.212 \mathrm{~mm}$ (CALDAS, 2006). 
Valença - RJ está inserido no Bioma Mata Atlântica e sua vegetação original é classificada como Floresta Estacional Semidecidual (CALDAS, 2006). A vegetação predominante do município encontra-se reduzida a alguns remanescentes florestais fragmentados, e pastagens (IBGE, 2019). A área de Mata Atlântica no município é estimada em 20.611 hectares, representando 15,8\% do município (COMITÊ DE BACIAS HIDROGRÁFICAS, 2017).

O presente trabalho teve o caráter quali-quantitativo realizado através de visitação a todas as vias da área de estudo e registro, com auxílio de fichas de campo das árvores presentes. O método utilizado foi a observação intensiva do local e levantamento total (censo) da arborização viária com o auxílio de um formulário pré-elaborado para a coleta de dados (Figura 2). Foram registradas as características das vias, como dimensões e tipo predominante de ocupação e trânsito. Para a medição de calçamento e ruas foram utilizadas trenas de 20 metros. Sobre as árvores, foi feita a identificação, no campo, da espécie, e, para as que ainda persistiam alguma dúvida, foi feita a coleta de material botânico para identificação com auxílio de literatura especializada (LORENZI et al., 2003; LORENZI, 2008; LORENZI, 2009a; 2009b).

\begin{tabular}{|c|c|c|c|c|c|}
\hline $\begin{array}{l}\frac{\pi}{2} \\
\frac{\pi}{0} \\
\text { ஸ) } \\
\frac{0}{0} \\
\frac{\pi}{0}\end{array}$ & \multicolumn{5}{|c|}{ 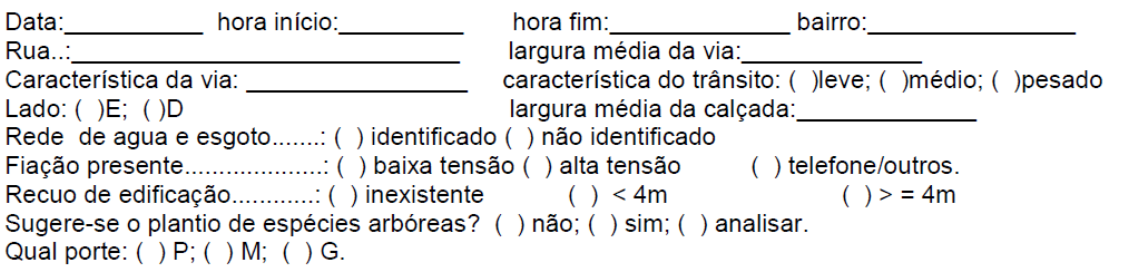 } \\
\hline $\mathbf{N}$ & $\begin{array}{l}\text { TÁXON/ } \\
\text { COORDENADAS }\end{array}$ & CAP $(\mathrm{cm})$ & $\mathrm{HC}(\mathrm{m})$ & $\mathrm{HT}(\mathrm{m})$ & OBSERVAÇÕES \\
\hline & $\begin{array}{l}\text { ESPÉCIE: } \\
\text { ORIGEM (N/E): } \\
\text { REF. DO IMÓVEL: } \\
\text { COORDENADA: }\end{array}$ & & & & 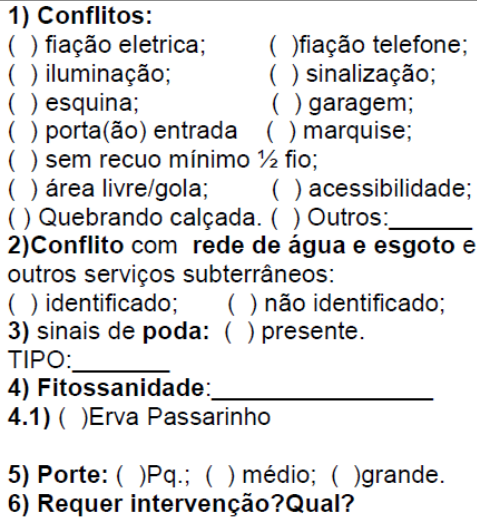 \\
\hline
\end{tabular}

Nota: Características da via (Residencial, Comercial, Mista, Industrial). Fitossanidade: 1 - Boa, 2 - media/regular; 3- Ruim. Conflitos com acessibilidade (conforme NBR 9050/94). Lado da rua/calçada: sentido crescente da numeração da via. Requer intervenção, qual (analisar, substituir, podar); origem: N-Nativa; E- Exótica

Figura 2. Formulário de campo elaborado para o presente estudo Figure 2. Field form prepared for the present study

Para atualização da nomenclatura científica das espécies vegetais encontradas foram utilizadas a mesma definição utilizada por Freitas, Pinheiro, Abrahão (2015) e Silva et al. (2016), 
onde o sistema de taxonomia vegetal adotado foi o Angiosperm Phylogeny Group IV (ANGIOSPERM PHYLOGENY GROUP IV, 2016), com a descrição taxonômica conferida junto aos bancos de dados disponibilizados pelo sítio: "Flora do Brasil" do Jardim Botânico do Rio de Janeiro (FLORA DO BRASIL, 2020) e do Missouri Botanical Garden sendo cada espécie agrupada conforme sua origem.

Foram feitos registros dendrométricos, como circunferência acima do peito (CAP), altura total estimados visualmente e outros que pudessem embasar o manejo, em especial os registros de conflitos capazes de gerar danos/problemas, com elementos urbanos, como a fiação, iluminação, sinalização, esquina, garagem, área livre de calçada, recuo mínimo do meio fio e serviços subterrâneos (Figura 2). Foram registradas as árvores com sinais de podas pretéritas e foi feito o registro também das árvores que demonstravam a necessidade de intervenção, devido a riscos diversos. Foram registradas as coordenadas geográficas com GPS de navegação Garmim eTrex de todos os indivíduos arbóreos estudados. As alturas totais dos indivíduos foram classificadas conforme trabalho realizado por Silva et al. (2016), cuja escolha se dá no limite de classe de 9,40 devido a fiação elétrica ocorrer na faixa de 7,20 metros (Baixa Tensão) e de 8,20 a 9,40 metros (Alta tensão), conforme trabalho realizado por Pivetta e Silva Filho (2002).

Os dados obtidos foram compilados e processados por meio de tabelas, utilizando-se o programa $E x c e(\AA$. A densidade relativa de cada espécie foi calculada pela relação: Número de árvores encontrado da espécie/Número total de árvores x 100. Os mapas foram elaborados utilizando o programa ArcGIS 10.2.

\section{RESULTADOS E DISCUSSÃO}

Foram identificados 302 indivíduos arbóreos presentes em 41 das 101 ruas estudadas, distribuídos em 55 espécies dos quais uma indeterminada, 52 gêneros, sendo um indeterminado, 30 famílias botânicas das quais 29 famílias identificadas e uma indeterminada, e quatro indivíduos mortos.

As 10 espécies mais representativas (Tabela 1) correspondem a 71,24\% dos indivíduos inventariados, onde os maiores destaques foram registrados para Bauhinia variegata responsável por $74(24,51 \%)$ dos indivíduos encontrados, seguido respectivamente por Licania tomentosa com 48 indivíduos (15,89\%), Ligustrum lucidum com 21 (6,96\%), e Lagerstroemia indica com 16 (5,31\%).

Tabela 1.As 10 espécies com maior ocorrência no inventário arbóreo viário da Zona Central, Valença - RJ Table 1. The 10 species with the higher occurrence in the arboreal inventory of the Central Zone, Valença - RJ 


\begin{tabular}{lll}
\hline Nome Científico & Nome Comum & Percentual $^{*}$ \\
\hline Bauhinia variegata L. & pata-de-vaca & 24,50 \\
\hline Licania tomentosa (Benth.) Fritsch & oiti & 15,89 \\
\hline Ligustrum lucidum W. T. Aiton & ligustro & 6,95 \\
\hline Lagerstroemia indica L. & extremosa & 5,31 \\
\hline Poincianella pluviosa (DC.) L.P. Queiroz & sibipiruna & 3,64 \\
\hline Nerium oleander L. & espirradeira & 3,31 \\
\hline Delonix regia (Bojer ex Hook.) Raf. & flamboyant & 2,98 \\
\hline Psidium guajava L. & goiabeira & 2,98 \\
\hline Terminalia catappa L. & amendoeira & 2,98 \\
\hline Magnolia champaca (L.) Baill. ex Pierre & magnólia & 2,65 \\
\hline
\end{tabular}

$\left(^{\star}\right)$ Percentual em relação ao número de indivíduos arbóreos encontrados no inventário

As quatro espécies com maiores valores percentuais em relação ao número de indivíduos encontrados no inventário correspondem a pouco mais da metade $(52,67 \%)$ das espécies encontradas no levantamento arbóreo realizado. Os outros 47,33 \% estão divididos em 51 espécies diferentes. Para Silva et al. (2016), a prática de concentração de indivíduos arbóreos em uma ou duas espécies é comum no Brasil, e Bauhinia variegata e Licania tomentosa são espécies comumente encontradas de forma expressiva na arborização das ruas em cidades e regiões brasileiras (PESTANA; ALVES; SARTORI, 2011).

Neste estudo, as 101 ruas inventariadas estão distribuídas em 12 bairros da Zona Central, onde mais da metade dessas ruas não apresentaram arborização viária. Apenas 41 delas $(40,59 \%)$ apresentaram ao menos um indivíduo arbóreo, havendo uma distribuição bastante irregular dos espécimes arbóreos na Zona Central de Valença. Esta variação irregular pode relacionar-se com as características urbanas dos imóveis, pois conforme relata Iwama (2014), que ao realizar estudo da distribuição de árvores em Martinópolis - SP e Pirapozinho $\mathrm{SP}$, destaca que a arborização se diferencia com as características dos bairros devido a variação das funções dos padrões construtivos, e uso residencial, ou comercial dos imóveis.

Os resultados das alturas totais dos indivíduos encontram-se na Figura 3, separados em três classes (< 6 metros; > 6 e < 9,40 metros; e > 9,40 metros). Ao analisar os indivíduos arbóreos no presente estudo, com base na altura, 75,50 \% (228) apresentaram altura inferior a seis metros, um número bastante expressivo comparado com as demais classes de alturas. $A$ classe de altura maior que seis metros e menor que 9,40 metros apresentou $18,87 \%$ (57) do total de indivíduos, enquanto que maior que 9,40 metros foi apenas 5,63 \% (17). 


\section{Número de indivíduos x Altura}

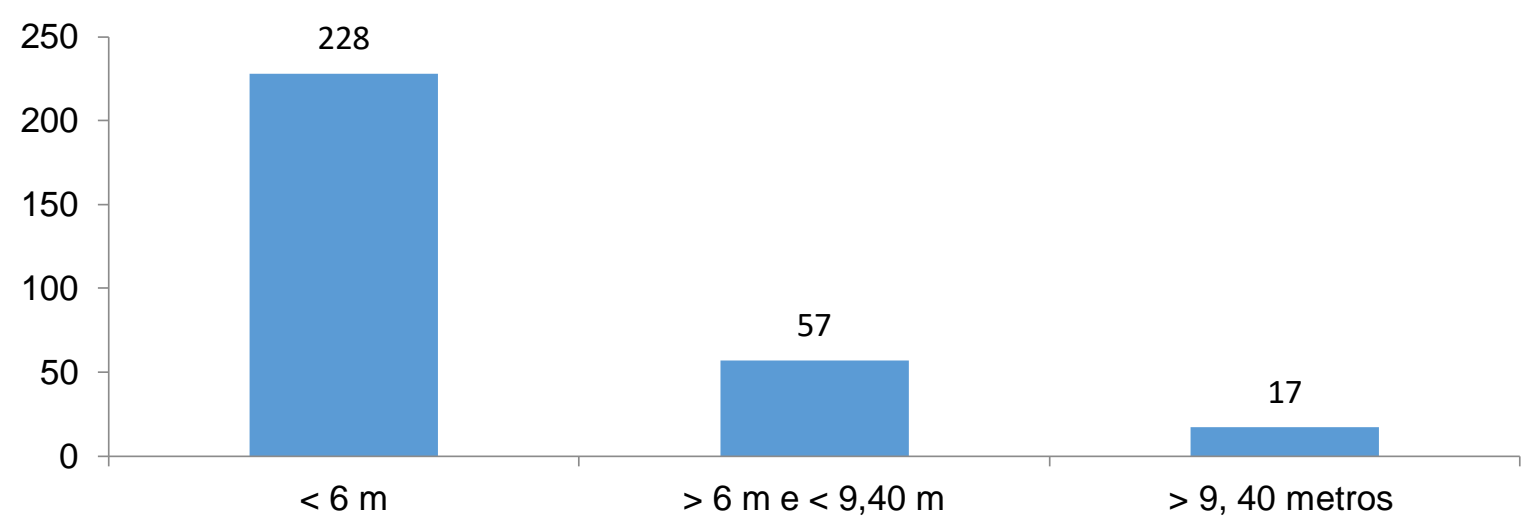

Figura 3. Indivíduos arbóreos do inventário viário da Zona Central de Valença - RJ separados por três classes de altura, totalizando 302 indivíduos

Figure 3. Arboreal individuals from the road inventory of the Central Zone of Valencia - RJ separated by three height classes, totaling 302 individuals

Almeida e Neto (2010) apontam ao analisarem a arborização urbana das cidades de Matupá e Colíder na região norte do Mato Grosso, que menos de 50 \% dos indivíduos plantados estavam sob a fiação elétrica e a altura média encontrada dos indivíduos arbóreos foi de 3 e 4,7 metros respectivamente. Em contrapartida, no trabalho de Silva et al. (2016), os valores em relação as redes elétricas de baixa tensão, a classe de maior altura apresentou ocorrência de $2,6 \%$, sendo as alturas maiores dominantes, configurando conflitos com as redes elétricas de baixa tensão. Para corroborar, Silva, Silveira e Teixeira (2008) relatam que nas espécies de médio porte geralmente há coincidência com a altura dos fios e copa das árvores, e uma vantagem apresentada pelas espécies de grande porte, é que ao ultrapassarem os fios, estes e a iluminação pública não são prejudicados.

No estudo realizado pelos referidos autores na avaliação da arborização de vias públicas de uma área da região oeste da cidade de Franca - SP, 76,8 \% dos indivíduos apresentaram altura estimada inferior ou igual a seis metros. Porém, nos indivíduos sob a fiação, o valor foi de $87 \%$ para 217 indivíduos, indicando que conflitavam, possivelmente, apenas com os cabos aéreos de telefone, pois os cabos de energia elétrica encontram-se a partir dos seis metros.

$\mathrm{Na}$ Tabela 2 são apresentados os percentuais de cada tipo de conflito observados na arborização do Centro do município de Valença, onde cada indivíduo arbóreo pode apresentar mais de um conflito com os elementos urbanos. Esses dados também estão espacializados na Figura 4, como forma de facilitar a visualização da distribuição dos conflitos (PEREIRA et al., 2019). Um grande número de árvores apresentou mais de um tipo de conflito, onde dos 302 indivíduos arbóreos, os conflitos com a fiação se destacaram, atingindo para o caso de fiação telefônica, quase a metade do total de árvores e pouco menos de 40 \% no caso de fiação elétrica. 
Os conflitos observados com o calçamento também foram numerosos, com mais de $17 \%$ de árvores quebrando a calçada. Os valores encontrados confirmam os que outros autores têm observado, com percentuais altos de conflitos com a fiação e com o calçamento. Caiche et al. (2016), em estudo sobre os registros de supressão de árvores na cidade de São Carlos - SP, mencionam que as maiores motivações para supressão de árvores estão relacionadas ao conflito com elementos de infraestrutura, em especial o passeio público.

Tabela 2. Tipos de conflitos observados no Inventário da arborização da Zona Central de Valença-RJ Table 2. Types of conflicts observed in the road Afforestation Inventory of the Central Zone of Valença-RJ

\begin{tabular}{|c|c|c|}
\hline Tipo de conflito & $\begin{array}{l}\text { Número de árvores } \\
\text { apresentando conflitos }\end{array}$ & $\begin{array}{c}\text { \% de árvores apresentando } \\
\text { conflitos em relação } \\
\text { ao total de árvores inventariadas }\left({ }^{*}\right)\end{array}$ \\
\hline Fiação de telefone & 136 & 45,03 \\
\hline Fiação elétrica & 115 & 38,08 \\
\hline Acessibilidade & 74 & 24,50 \\
\hline Área livre/gola & 65 & 21,52 \\
\hline Quebrando calçada & 52 & 17,22 \\
\hline Iluminação & 30 & 9,93 \\
\hline Portão entrada & 29 & 9,60 \\
\hline Garagem & 15 & 4,97 \\
\hline Recuo meio fio & 12 & 3,97 \\
\hline Esquina & 10 & 3,31 \\
\hline Sinalização & 9 & 2,98 \\
\hline Marquise & 4 & 1,32 \\
\hline
\end{tabular}

Diversos autores apontam que uma via estreita pode ocasionar problemas entre a disputa do espaço aéreo do espécime arbóreo na via, mesmo em casos de ausência de fiação e calçadas largas, pois o porte (pequeno, médio, ou grande) do indivíduo arbóreo, a formação de seu fuste e o tipo de copa podem influenciar diretamente em problemas de injúria mecânica ocasionada pelo trânsito local de ônibus ou caminhões, sobretudo as de características de médio a pesado, pois os veículos com maiores alturas em contato com o fuste, galhos, demonstram de certa forma a falta de sincronismo entre o planejamento e a arborização (PIVETTA; SILVA FILHO, 2002; CEMIG, 2011; CHAVES; SILVA; AMADOR, 2013).

A falta de gola das árvores (pouco mais de 20\%), e acessibilidade (mais de $24 \%$ ) também refletem problemas relacionadas à falta de planejamento e critério no plantio das espécies. Assim, por conseguinte, a ausência de manutenção dos passeios públicos gera dificuldades na locomoção de pedestres, e injúrias nos indivíduos arbóreos. Mayer, Oliveira Filho e Bobrowski (2015) realizaram análise espacial de conflitos da arborização de vias públicas para 
a cidade de Irati - PR e observaram que a altura de bifurcação do fuste abaixo de 1,80 metros, se constitui num problema ao trânsito livre dos pedestres nas calçadas.
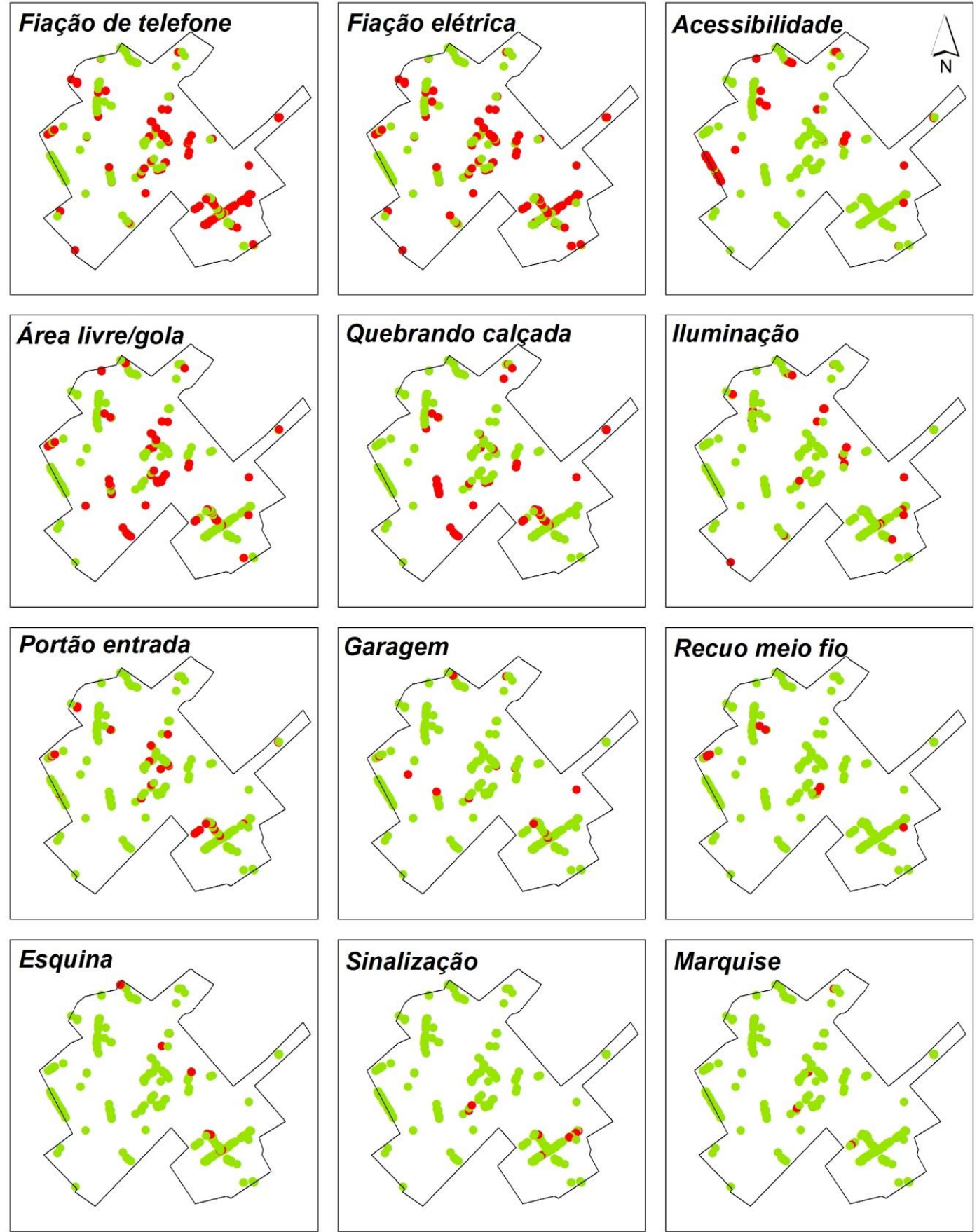

\section{Legenda}

- Conflito $\leftleftarrows$ Centro de Valença

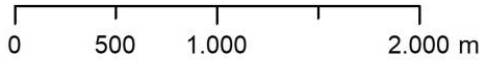

- Sem conflito

Figura 4. Desenho esquemático da distribuição das árvores com os diferentes tipos de conflitos da Zona Central de Valença-RJ

Figure 4. Schematic drawing of tree distribution with the different types of conflicts in the Central Zone of Valença-RJ 
O centro de Valença apresenta uma diversidade grande de vias, com dimensões variadas, espelhando a história e a dinâmica ocorridas naquela localidade. Um número relativamente grande de vias e calçadas mais estreitas, em parte herança ainda no período colonial, convive com vias um pouco mais largas, com usos bastante diversificados, mas com predominância residencial. Na Tabela 3 é possível observar estas características. Vale destacar que mais de $60 \%$ das vias apresentaram calçadas com larguras inferiores a 2,0 m, o que torna a possibilidade de arborização e o seu manejo um desafio complexo.

Tabela 3. Largura média do calçamento nas vias levantadas no Centro da cidade de Valença - RJ Table 3. Average width of the sidewalks in the surveyed roads in the Central Zone of Valença - RJ

\begin{tabular}{ccc}
\hline Largura média da calçada $(\mathbf{m})$ & Número de calçadas & \% de calçadas \\
\hline$<1,5$ & 63 & 31,2 \\
\hline$>=1,5 \mathrm{e}<2$ & 69 & 34,1 \\
\hline$>=2 \mathrm{e}<2,40$ & 37 & 18,3 \\
\hline$>=2,40 \mathrm{e}<3$ & 25 & 12,4 \\
\hline$>=3$ & 8 & 4,0 \\
\hline Total & $\mathbf{2 0 2}$ & $\mathbf{1 0 0}$ \\
\hline
\end{tabular}

É possível observar as características predominantes das ruas estudadas quanto ao uso na Figura 5, onde a característica residencial com 67,3 \% superam as de uso misto e comercial. Este fato associa-se a característica de predomínio de trânsito leve na Zona Central do município, e pelo porte pequeno da cidade, e estrutura urbana de ruas e calçadas estreitas.

\section{Característica da Via (\%)}

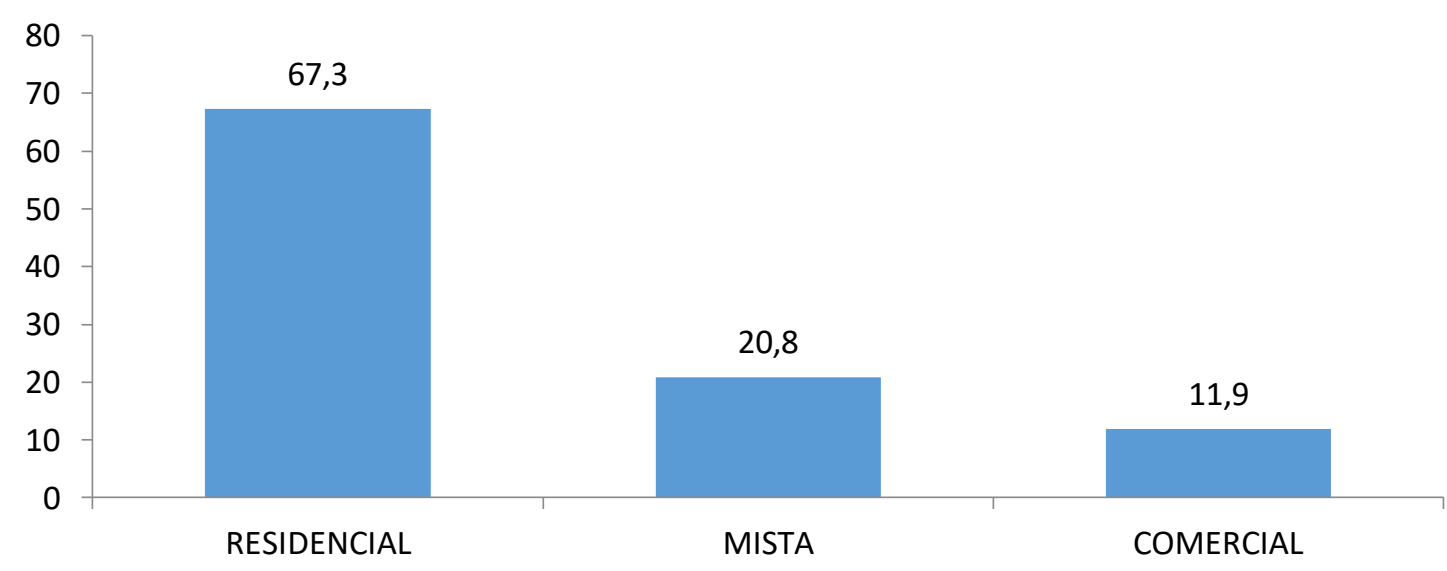

Figura 5. Tipo de ocupação principal das vias inventariadas da Zona Central de Valença, Estado do Rio de Janeiro

Figure 5. Type of main occupation of the inventoried roads of the Center of Valença, State of Rio de Janeiro

Na Tabela 4 é apresentado o número de conflitos observados pelas dez espécies com maior densidade relativa no centro de Valença. Espécies como a extremosa e a espirradeira são 
de pequeno porte e recomendadas principalmente por empresas distribuidoras de energia, para evitar conflitos entre a arborização e a fiação (CEMIG, 2011).

Tabela 4. Número de conflitos registrados pelas dez espécies de maior densidade relativa presentes na arborização do Centro da cidade de Valença, RJ

Table 4. Number of conflicts recorded by the ten species with higher relative density present in the afforestation of the Central Zone of Valença-RJ

\begin{tabular}{lccc}
\hline \multicolumn{1}{c}{ Nome Científico } & $\begin{array}{c}\text { Densidade } \\
\text { Relativa (\%) }\end{array}$ & Número de árvores & Número conflitos \\
\hline Bauhinia variegata & 24,5 & 74 & 143 \\
\hline Licania tomentosa & 15,9 & 48 & 78 \\
\hline Ligustrum lucidum & 6,9 & 21 & 67 \\
\hline Lagerstroemia indica & 5,3 & 16 & 40 \\
\hline Poincianella pluviosa & 3,6 & 11 & 24 \\
\hline Nerium oleander & 3,3 & 10 & 21 \\
\hline Terminalia catappa & 2,9 & 9 & 19 \\
\hline Delonix regia & 2,9 & 9 & 22 \\
\hline Psidium guajava & 2,9 & 9 & 11 \\
\hline Magnolia champaca & 2,6 & 8 &
\end{tabular}

É possível observar que as espécies inventariadas apresentaram uma média de cerca de dois conflitos por árvore ou abaixo disto, com exceção de Ligustrum lucidum que chegou a cerca de três conflitos por árvore. Vale a pena destacar a Lagerstroemia indica e a Nerium oleander que embora sejam espécies de menor porte e/ou de menor massa foliar, apresentaram especialmente problemas relacionados a conflitos com a fiação.

Vale ressaltar também, a Bauhinia variegata, espécie com maior densidade no local inventariado, também com cerca de dois conflitos por árvore, que apresenta formas de expansão da copa peculiares e que podem servir de exemplo para se analisar o planejamento e o manejo, incluindo seus custos de manutenção. Esta espécie, originária da Índia, possui atributos para uso paisagístico sobretudo na arborização urbana, sendo uma das mais cultivadas nas ruas das cidades do sudeste do Brasil, apresentando geralmente porte de até 10 metros de altura (LORENZI et al., 2003), no entanto tem uma capacidade alta de lançamento de ramos laterais, e ramagem densa formando copa mais ou menos globosa (LORENZI et al., 2003) com expansões que podem alcançar vários metros além do tronco que por conseguinte geram a necessidade de podas constantes.

O percentual de árvores com sinais de poda pretérita em relação ao número total de árvores inventariadas foi de 69 \% (209 indivíduos) e o percentual de árvores que requerem intervenções foi de $31 \%$ das árvores (95 indivíduos). Estes valores são bastante altos e devem ser motivo de atenção por parte dos gestores, tendo em vista o dispêndio de recursos para a realização dos serviços de poda, remoção do material lenhoso e foliar, assim como a destinação correta dos resíduos de poda para os locais apropriados. 
Um número significativo de levantamentos têm demonstrado a urgência de se buscar soluções para os conflitos entre a arborização e outras estruturas urbanas no sentido de minimizar as podas, e segundo Silva et al. (2016), um dos principais problemas existentes na arborização viária relaciona-se ao confronto do espaço físico entre as árvores, com calçamentos, redes aéreas de distribuição de energia, fachadas e edificação.

Adicionalmente, as cidades apresentam territórios com dinâmicas diferenciadas e que se refletem na maior ou menor presença de áreas verdes e de arborização. Zonas mais valorizadas e com atenção contínua do poder público convivem, por exemplo, muitas vezes, com zonas negligenciadas, onde os espaços verdes são precários ou mesmo não existem. Da mesma forma, zonas com histórico e dinâmica diferenciados devem ser diagnosticadas e sistematizadas, de modo a facilitar e aproveitar todo o potencial de uso de elementos verdes, sem que isto gere conflitos e gastos desnecessários.

A existência de conflitos entre a arborização e outros elementos da cidade pode resultar de diferentes dinâmicas no mosaico urbano e a sua categorização pode ser um passo útil para o enfrentamento do problema. Em áreas em que estes conflitos acontecem, é possível identificar espaços em que a própria morfologia urbana impede ou inibe fortemente a arborização, e os que resultam da falta ou erro de planejamento por parte do poder público. A identificação destes problemas pode ajudar na diagnose e na sua diminuição.

Pelos dados coletados, o Centro de Valença apresenta como maior desafio espaços que se constituem em heranças do período colonial, onde a morfologia das cidades não incorporava a arborização, com ruas e calçadas estreitas. Estes espaços também não comportam fiações e o planejamento deve considerar a mudança de linhas aéreas para subterrâneas e o plantio e/ou a manutenção de elementos arbóreos, quando possível, que não conflitem com o acesso e as edificações. Os dados observados apontam também para um número grande de conflitos gerados pela invasão de elementos da estrutura urbana sobre a arborização ou vice-versa.

\section{CONCLUSÕES}

O inventário se mostrou eficiente e poderá ser utilizado em outros distritos do município, bem como em situações similares, considerando as dimensões e características da zona estudada. Concomitantemente, cria uma base importante para futuros planos de gestão.

O levantamento dos conflitos entre a arborização e outras estruturas urbanas do Centro da cidade de Valença mostrou percentuais altos para os conflitos com a fiação, o calçamento e o acesso, a exemplo de outros inventários realizados em cidades brasileiras. Um percentual grande de ruas e calçadas apresentou dimensões abaixo de dois metros de largura, o que tem 
consequências diretas na ocorrência dos conflitos com calçamento e acesso.

As informações obtidas permitem um melhor manejo da arborização, buscando compatibilizar os espaços de convivência e manter as funções e benefícios trazidos pela cobertura arbórea.

\section{REFERÊNCIAS}

ALMEIDA, D.N.; NETO, R.M.R. Análise da arborização urbana de duas cidades da região norte do estado de Mato Grosso. Revista Árvore, Viçosa-MG, v.34, n.5, p. 899-906, 2010.

ALVARES, C.A., STAPE, J.L., SENTELHAS, P.C., GONÇALVES, J.L.M.; SPAROVEK, G. Köppen's climate classification map for Brazil. Meteorologische Zeitschrift, v. 22, n. 6, p. 711728, 2013.

ANGIOSPERM PHYLOGENY GROUP IV. An update of the Angiosperm Phylogeny Group classification for the orders and families of flowering plants: APG IV. Bot. J. Linnean Soc. v.181, p. 1-20, 2016.

CAICHEL, D.T.; SILVA, S.R.M.; VIANA, S.M.; SILVA R.S. Análise da supressão da arborização viária na cidade de São Carlos/SP no período de 2004 a 2013. Revista da Sociedade Brasileira de Arborização Urbana, Piracicaba, v.11, n.3, p. 93-103, 2016.

CALDAS, A.J.F. Geoprocessamento e análise ambiental para Determinação de corredores de hábitat na Serra da Concórdia, Vale do Paraíba - RJ. Rio de Janeiro, 2006. 110f. Dissertação (Mestrado em Ciências) - Universidade Federal Rural do Rio de Janeiro, Rio de Janeiro, 2006.

CHAVES, A.M.S.; SILVA, A.S.; AMADOR, M.B.M. Ausência de sincronia entre planejamento e a arborização urbana: um estudo de caso na Avenida Rui Brabosa em Garanhuns - PE. Revista Nacional de Gerenciamento de Cidades, Tupã, v.1, n.3, p.54-71, 2013.

COMITÊ DE BACIAS HIDROGRÁFICAS - MÉDIO PARAÍBA DO SUL (CBH-MPS). Atlas das Microbacias da Região Hidrográfica Médio Paraíba do Sul. Disponível em <http://www.cbhmedioparaiba.org.br/conteudo/atlas-CBH-MPS.pdf. $>$ Acesso em: 23 Abr. 2017.

COMPANHIA ENERGÉTICA DE MINAS GERAIS (CEMIG). Manual de arborização. Belo Horizonte: Cemig/Fundação Biodiversitas, 2011. 112p.

FLORA DO BRASIL 2020 EM CONSTRUÇÃO. Jardim Botânico do Rio de Janeiro. Disponível em <http://floradobrasil.jbrj.gov.br/>. Acesso em: 3 jan. 2018.

FREITAS, W.K., PINHEIRO, M.A.S., ABRAHAO, L.L.F. Análise da Arborização de Quatro Praças no Bairro da Tijuca, RJ, Brasil. Floresta e Ambiente, Seropédica, v. 22, n. 1, p. 23-31, 2015.

INSTITUTO BRASILEIRO DE GEOGRAFIA E ESTATíSTICA (IBGE). Censo Demográfico, 2019. Disponível em <http://www.ibge.gov.br> Acesso em: 19 de dez. 2019.

IWAMA, A.Y. Indicador de Arborização Urbana como Apoio ao Planejamento de Cidades Brasileiras. Revista da Sociedade Brasileira de Arborização Urbana, Piracicaba, v.9, n.3, p 156-172, 2014. 
LORENZI, H. Árvores brasileiras: manual de identificação e cultivo de plantas arbóreas nativas do Brasil. Nova Odessa: Instituto Plantarum, 2008. v.1, 5.ed. 384p.

LORENZI, H. Árvores brasileiras: manual de identificação e cultivo de plantas arbóreas nativas do Brasil. Nova Odessa: Instituto Plantarum, 2009a. v.2, 3.ed. 384p.

LORENZI, H. Árvores brasileiras: manual de identificação e cultivo de plantas arbóreas nativas do Brasil. Nova Odessa: Instituto Plantarum, 2009b. v.3, 1.ed. 384p.

LORENZI, H.; SOUZA, H.M.de; TORRES, M.A.V.; BACHER,L.B. Árvores Exóticas no Brasil: madeireiras, ornamentais e aromáticas. Nova Odessa: Instituto Plantarum, 2003. 385p.

MARTELLI, A.; BARBOSA JR., J. Incidência e fatores causais das supressões da arborização urbana no município de Itapira, Estado de São Paulo. Rev. Acad., Ciênc. Agrár. Ambient., Curitiba, v. 9, n. 2, p. 215-222, abr./jun. 2011.

MAYER, C.L.D., OLIVEIRA FILHO, P.C., BOBROWSKI, R. Análise espacial de conflitos da arborização de vias públicas: caso Irati, Paraná. Floresta, Curitiba, v. 45, n. 1, p. 11, 2015

PEREIRA, A.W.; ARTHUR JUNIOR, J.C.; MENDONÇA, B.A.F.de; SANTOS, C.J.F.; GIÁCOMO, R.G.; ARAÚJO, E.J.G.de; SILVA, E.V.da. Análise quali-quantitativa da arborização urbana de dois bairros do municipio do Rio de Janeiro por meio do geoprocessamento. Revista da Sociedade Brasileira de Arborização Urbana, Curitiba, v.14, n.2, p. 43-61, 2019

PESTANA, L.T.C.; ALVES, F.M.; SARTORI, A.L.B. Espécies arbóreas da arborização urbana do centro do município de Campo Grande, Mato Grosso do Sul, Brasil. Revista da Sociedade Brasileira de Arborização Urbana, Piracicaba, v. 6, n. 3, p. 01-21, set. 2011.

PIVETTA, K.F.L.; SILVA FILHO, D.F. Boletim Acadêmico Série Arborização Urbana. Jaboticabal: UNESP/FCAV/FUNEP, 2002.

SILVA, K.A.R.; LELES, P.S.S.; GIÁCOMO, R.G.; MENDONÇA, B.A.F. Diagnóstico e uso de geoprocessamento para manejo da arborização urbana do bairro centro da cidade do Rio de Janeiro - RJ. Revista da Sociedade Brasileira de Arborização Urbana, Piracicaba, v.11, n.4, p. 98-114, 2016.

SILVA, M.D.M.; SILVEIRA, R.P.; TEIXEIRA, M.I.J.G. Avaliação da arborização de vias públicas de uma área da região oeste da cidade de Franca/SP. Revista da Sociedade Brasileira de Arborização Urbana, Piracicaba, v. 3, n. 1, p. 19-35, 2008.

TEIXEIRA, I.F.; SILVA, R.M. da; TATSCH, G.L. Compatibilidade da arborização de ruas da Avenida Celestino Cavalheiro, São Gabriel-RS. Floresta e Ambiente, Seropédica, v. 18, n. 4 p. 438-450, 2011. 